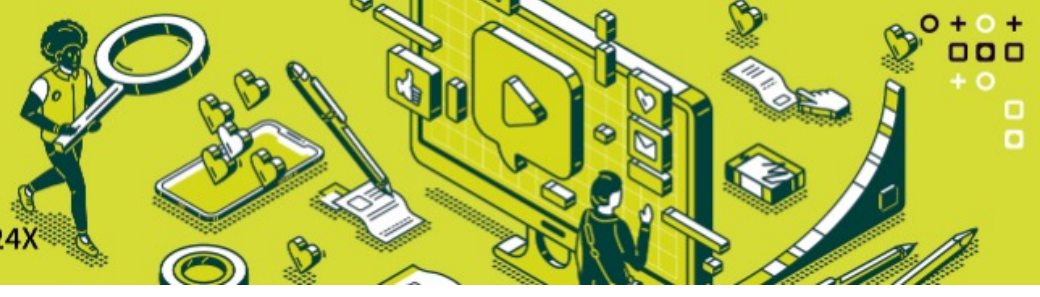

\title{
OS DISCURSOS SOBRE O ESTUDO REMOTO DA FLAUTA DOCE DURANTE A PRIMEIRA ONDA DA PANDEMIA DA COVID 19 NO ALTO DO PASCOAL ZONA NORTE DO RECIFE
}

DISCOURSES ABOUT REMOTE STUDY OF RECORDER DURING THE FIRST PANDEMIC WAVE OF THE COVID 19 IN ALTO DO PASCOAL NORTHERN RECIFE

\author{
${ }^{1}$ Jevison Santa Cruz; ${ }^{2}$ Maria do Rosário Alves Leite \\ ${ }^{1}$ Centro Universitário de Araras - UNAR - jevison_maestro@hotmail.com \\ ${ }^{2}$ Centro Universitário de Araras - UNAR - rosarioaleite@hotmail.com
}

Resumo: O presente estudo objetivou investigar a dinâmica do estudo da flauta doce via aulas remotas, conforme a portaria $n^{\circ} 343$ do Ministério da Educação, que autorizou o ensino por meios digitais em razão da epidemia de COVID 19. O campo de pesquisa foi uma organização não governamental, situada na comunidade do Alto do Pascoal, em Recife-PE. Como aporte metodológico utilizou-se a observação das aulas e a realização de entrevistas semiestruturadas com estudantes e pais. De cunho qualitativo, empregou-se a análise de discurso de linha francesa para o exame dos dados. No resultado identificou-se que o estudo da flauta doce promoveu: concentração, memorização, coordenação motora e organização coletiva; configurando-se assim como uma importante ferramenta terapêutica em tempos de pandemia.

Palavras-Chave: Flauta doce. estudo remoto. Análise de discurso.

\begin{abstract}
This present study aimed to investigate the dynamic of the recorder study through remote classes, according to the ordinance No. 343 from the Ministery of Education, authorizing teaching by digital ways because of the COVID 19 pandemic. The search field was a nongovernmental organization, located in Alto do Pascoal community in Recife state of Pernambuco. As a methodological support, classes observation was utilized and a semistructured interview was realized with the students and parents. With a qualitative formation, a French discourse analysis was applied to the examination of data. For result it was identified that the recorder study promoted: concentration, memorization, motor coordination and collective organization; configured so, as an important therapeutic tool in times of pandemic.
\end{abstract}

Key-words: Recorder. Remote study. Discourse Analysis. 


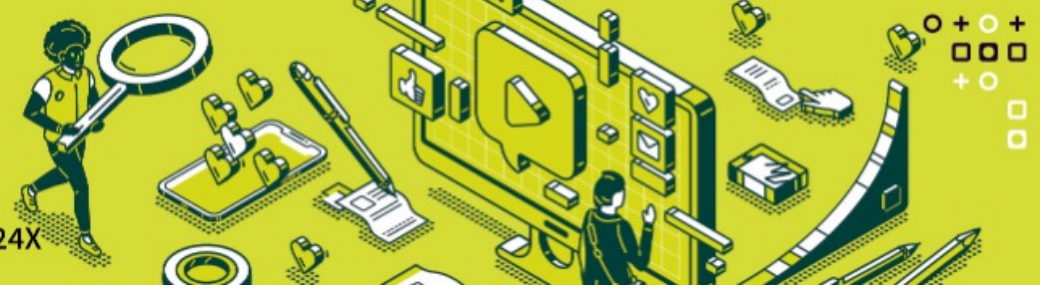

\section{INTRODUÇão}

As experiências no contato com a flauta doce por diferentes sujeitos são diversas, enquanto uns a amam, outros, já nem tanto! Mas, não estariam os preconceitos construídos em torno do instrumento, pautados numa prática de ensino inadequada? Afinal, a flauta doce não é apenas um apito! Desta maneira, a história da música informa que o adjetivo"doce", estaria relacionado à beleza sonora e à capacidade do instrumento proporcionar ao seu ouvinte um estado de espírito sereno (AGUILAR, 2017).

A arqueologia comunica que a flauta doce é um instrumento musical antiquíssimo, de origem imprecisa e encontrado no período da pré-história (BENASSI, 2013). Popularmente suas partes fazem alusão ao corpo humano dividido em cabeça, corpo e pé, contudo, caracteriza-se por um tubo dividido em três partes: na primeira parte, a extremidade superior, é composta por um apito e por uma janela na qual o som é emitido; na segunda, encontra-se a extensão do tubo onde localiza-se a maioria dos furos para o dedilhado das notas musicais e a terceira, traz a extremidade inferior de forma circular aberta (AGUILAR, 2017).

Conforme Benassi (2013), um achado recente vinculado à Universidade de Tubingen na Alemanha, se encontrou uma flauta de osso perto dos 42.000 anos de existência, constatando dessa forma seu passado milenar. Já segundo Barbosa (2020), é apenas no século XI que aparecem os primeiros comentários sobre ela, sendo evidenciada consideravelmente diante dos achados de partituras, "afrescos e tapeçarias" (AGUILAR, 2017, p. 31) dos séculos XV e XVI que demonstravam sua prática.

De fato, é durante o período do Renascimento e de boa parte do período Barroco, que se observa a ascensão e o declínio do instrumento. A priori, sendo utilizado frequentemente nas apresentações da chamada música de câmara, ou seja, execução musical em pequenas salas de nobres e com poucos músicos tocando em conjunto, logo, em tal formato de apresentação musical se desenhava o protótipo da orquestra (BENNETT, 1986). Segundo Aguilar (2017), durante a Renascença os instrumentos musicais passaram a ser identificados por sua intensidade sonora, estando a flauta doce inserida no grupo dos instrumentos considerados mais delicados como: "harpa, saltério, alaúde, órgão portátil, vieles e rabecas" (AGUILAR, 2017, p. 36).

Com característica sonora agradável, a flauta se popularizou, passando a ser tocada tanto por músicos amadores quanto por profissionais, entretanto, sua execução estava veiculada "aos membros da corte e elites urbanas" (AGUILAR, 2017, p. 38). De acordo com Barbosa (2020), os reis ingleses Henrique VII e Henrique VIII, foram notáveis praticantes do instrumento; a paixão desse último, pelo referido instrumento, era tão característico que na descrição de seus bens, após sua morte em 1547, foi identificada a citação a 76 flautas (BARBOSA, 2020).

Nesse contexto massivo do instrumento, hipoteticamente, acredita-se que era utilizado como integrante da iniciação musical para o público infantil, da mesma forma que também auxiliava no estudo do canto, por considerar seu timbre sonoro próximo da voz humana (AGUILAR, 2017). A Posteriori, com a ampliação do conceito de orquestra, outro instrumento passou a ser evidenciado, o violino. Destarte, a flauta doce foi perdendo seu espaço, diante de suas limitações de tessitura e das recentes propostas musicais apresentadas pelos novos períodos iminentes, a saber: o Clássico e o Romântico.

Nessa evolução histórico musical, que propunha uma orquestra com instrumentos que oferecessem maior desenvoltura dinâmica e peso sonoro, a exemplo dos metais: trompas e trompetes, a flauta doce não tinha como competir, e por assim ser, passou a cair de vez em desuso. Benassi (2013) faz referência a 1750, como o ano do sepultamento da flauta doce, o tempo no qual sua utilização ficou apenas 


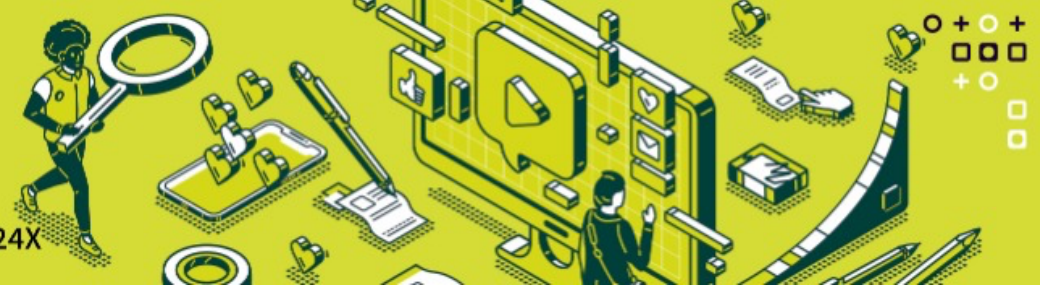

conformada a memória. Entretanto, mesmo com aquele cenário de extinção no século XVIII, a segunda metade do século XIX indicou uma proposta de resgate à pesquisa e à execução de instrumentos antigos, formalizando desta maneira um cenário propício ao ressurgimento da flauta, e agora, em variados espaços educacionais (BENASSI, 2013).

Considerando a iniciação musical, Gohn (2014) destaca o papel do ensino da música em projetos sociais e ONGs, por compreender que nesses espaços de variadas formações, inclusive a política, a música se constitui numa importante ferramenta de análise histórico-crítico social. Outrossim, o estudo da flauta doce no espaço social justifica-se, pelo fato dessa ser: a) de aquisição economicamente viável; b) proporcionar ao estudante uso técnico e de memorização; c) facilidade para inserir o estudante na prática de conjunto devido ao fácil diálogo com outros instrumentos; d) facilidade no ato do transporte, por ser um instrumento leve e pequeno.

Considerando a configuração brasileira no tocante ao ano de 2020, as expectativas e previsões para o país eram as mais otimistas possíveis, isto porque, em relação a economia se estimava um crescimento de $2 \%$ para o PIB, a redução gradual do desemprego, a diminuição das taxas de juros e a inflação controlada (BAND, 2020). Todavia, no início do mesmo ano, a população mundial foi surpreendida com o surgimento da (Sars-CoV-2), o novo coronavírus ou covid 19, uma doença desconhecida responsável por causar uma pandemia mundial ocasionando a morte de milhões de pessoas. Naquele contexto, a máxima era a do "fique em casa", como tentativa de reduzir a propagação do vírus e por consequência os casos letais da doença.

Neste cenário de distanciamento social desencadeador de problemas psicológicos diversos como crises de ansiedade, stress e depressão, um ambiente musical funcionaria como uma espécie de regulador emocional, uma vez que agiria na liberação da dopamina em determinadas regiões do cérebro, proporcionado sensações de prazer. Assim, diante de tal conjuntura sendo a música uma medicação natural para a saúde mental tanto para as crianças quanto para os adultos, o retorno às atividades de iniciação à flauta doce tornou-se uma condição necessária (VARGAS, 2012).

Naquele contexto, o presente estudo teve início a partir do seguinte questionamento: como as aulas de iniciação ao estudo da flauta doce poderiam ser retomadas num projeto social durante a primeira onda da covid 19 na zona norte da cidade do Recife? Com essa questão norteadora, a pesquisa formulou o seguinte objetivo: analisar a dinâmica do estudo da flauta doce via aulas remotas, em consonância com a portaria $n^{\circ} 343$ do Ministério da Educação, que autorizou as aulas por meios digitais a partir de 2020 (BRASIL, 2020).

\section{Metodologia dA PESQUiSA}

O presente estudo apresenta uma proposta metodológica qualitativa, pois oferece ao pesquisador um contato direto "com o ambiente e os sujeitos da pesquisa", Prodanov e Freitas (2013, p. 70). Por se tratar de um relato de experiência, o trabalho se configura como uma pesquisa descritiva, tendo como procedimentos técnicos o uso de ferramentas bibliográficas, observação sistemática e participante. Como instrumento de análise para a pesquisa, fizemos uso da Análise de Discurso de linha francesa (AD).

Para a coleta dos dados utilizamos a entrevista semiestruturada, Prodanov e Freitas (2013) reconhecem a importância dessa técnica para o levantamento dos dados em razão do nível de interação envolvido. Dessa feita, na constituição do corpus para a análise de discurso, a pesquisa contou com a participação de dez sujeitos, sendo cinco adultos e cinco crianças. Para a identificação de seus discursos a seguinte 


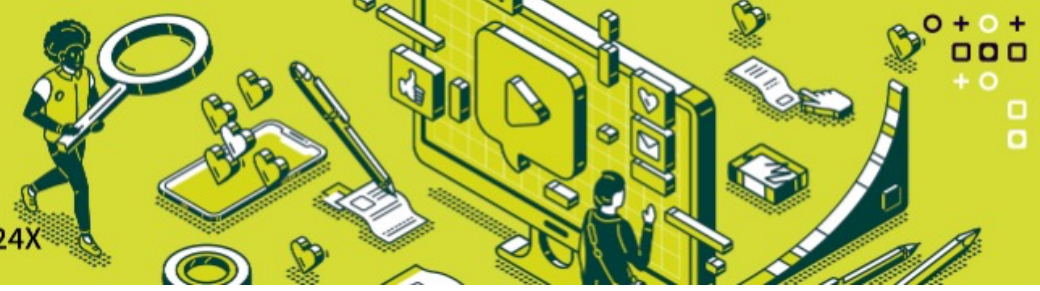

nomenclatura foi utilizada: Responsável e Estudante. Sublinha-se que tais colaboradores são: estudantes da flauta doce e seus respectivos responsáveis.

Para o embasamento teórico metodológico no estudo da flauta doce, utilizamos o Caderno de História e prática musical da Flauta Doce (DIRENE, 2014), componente da disciplina de arte para as escolas públicas de Curitiba. Por conseguinte, para as atividades futuras envolvendo a prática de conjunto, tomamos como base algumas das orientações trazidas pelo método Orff (MATEIRO; ILARI, 2011).

\section{Campo de pesquisa: Alto do Pascoal}

O presente estudo ocorreu no bairro alto do Pascoal localizado na (RPA 2) Região Político Administrativa na zona norte da cidade do Recife, estado de Pernambuco. A comunidade ali inserida, no que se diz respeito ao aspecto educacional, tem acesso a duas escolas estaduais e uma escola municipal, é limítrofe com o bairro Alto Santa Terezinha e conta com aproximadamente 7.703 habitantes, segundo última pesquisa do Instituto Brasileiro de Geografia e Estatística - IBGE, (CAMPOS, 2015).

Aponta-se que o bairro Alto do Pascoal sempre foi referência negativa nas páginas policiais dos principais veículos de comunicação da cidade, o que justifica o ofício encaminhado pela autoridade policial local ao delegado Seccional, solicitando melhores condições de trabalho. Tal documento sob o título "Recompletamento de efetivo e veículos", trouxe o seguinte dado sobre o contexto da comunidade:

A referida delegacia foi responsável por várias investigações que culminaram na prisão de traficantes e homicidas da região, com destaque para a prisão em flagrante de Assaltantes de Banco, prisão em flagrante de traficante com cerce de 15 quilos de crack (maior apreensão já feita por uma delegacia circunscricional) e a prisão em flagrante do assassinato do Comissário André Bezerra (CAMPOS, 2015, p. 1).

Observou-se que diante de tal descrição, a implantação e a manutenção de uma cultura de paz naqueles arredores, através de espaços educacionais não formais, se faziam necessário como maneira de colaborar com os ambientes formais já existentes e possibilitar a reflexão sobre a importância do respeito e empatia para com o outro, sendo a prática musical um dos caminhos para o alcance de tais metas (GOHN, 2014). Sob a ótica da promoção da cultura de paz na comunidade supracitada, a prática de iniciação ao estudo da flauta doce figurou como uma das oficinas oferecidas pelo MIM (Ministério Internacional de Misericórdia), "fundado em 28 de março de 2013 é uma Organização Social Civil de Interesse Público com fins não econômicos com prazo de duração por tempo indeterminado de caráter social e humanitário" (MINISTÉRIO INTERNACIONAL DE MISERICÓRDIA, 2013). Registrado sob o CNPJ de número 21.362.399/0001-20, o MIM traz como uma de suas finalidades em seu artigo 4 a "promoção do ensino musical e instrumental" (IBIDEM, p. 1), e antes da pandemia da covid 19, tinha suas atividades funcionando em espaço cedido por uma das igrejas protestantes encontradas na referida comunidade.

\section{RELATO DE EXPERIÊNCIA}

Em dias normais, anteriores a pandemia, a turma de iniciação ao estudo da flauta doce contava com dez alunos assíduos, contudo, diante do contexto pandêmico, os órgãos de saúde orientados pela organização mundial de saúde (OMS) difundiram medidas de prevenção e de controle da doença; tais diretivas conduziram a população a fazerem uso do protocolo chamado etiqueta respiratória que envolve higiene frequente das mãos, uso de máscaras cirúrgicas ou assemelhadas, proteção ao tossir e espirrar e limpar todos os objetos frequentemente utilizados (CORRÉA, 2020). Entretanto, dentre as medidas de controle 


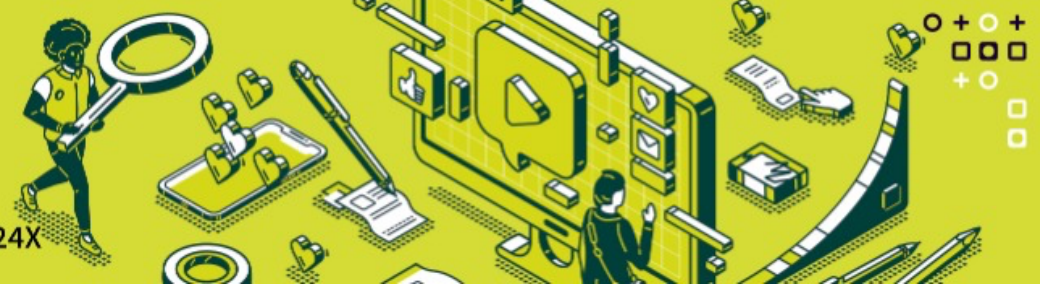

e prevenção da doença, a que mais causou estranheza à população dividindo opiniões e elevando tensões políticas foi a questão do isolamento social, o chamado Lockdown ${ }^{1}$.

Em Pernambuco, por exemplo, através do decreto $n^{\circ}$ 48.809, de 14 de março de 2020 (ALEPE, 2021), o governo do estado diante do aumento elevado de contaminados e temor do colapso na saúde pública, resolveu deixar a população em estado de quarentena, liberando presencialmente, apenas serviços essenciais. Considerando as incertezas e o terror vivenciado pela população mundial, a maneira considerada mais adequada à retomada das atividades educacionais se apresentou através do uso da tecnologia. A pandemia também expôs o problema de classes no Brasil, evidenciando a desigualdade na oportunidade de acesso aos veículos digitais: aparelho celular, tablet, computador e até mesmo internet (SOPRANA, 2020). Entendendo o contexto pandêmico e a necessidade de distanciamento social, o retorno às aulas de iniciação ao estudo da flauta doce via projeto social, teve seu início no trimestre outubro/dezembro de 2020, de maneira remota através da ferramenta Google Meet, sempre às sextas feiras, com uma hora de duração, de 17:00 às 18:00, totalizando 12 horas de atividades, sendo 10 horas vivenciadas remotamente e 02 horas presencialmente.

Ressalta-se que para esse momento presencial, o estado de Pernambuco já estava experimentando a 7ạ etapa do plano de convivência com o novo coronavírus (FOLHA DE PERNAMBUCO, 2020). Devido à carência de acesso à internet, cinco crianças com idades entre 8 e 10 anos voltaram aos encontros. De maneira geral os doze encontros foram distribuídos entre prática instrumental, contextualização de repertório, prática de conjunto e culminância com gravação audiovisual.

\subsection{A DINÂMICA DAS AULAS}

Como documento norteador para construção do repertório, mesmo se tratando de atividade realizada num projeto social, e não num ambiente burocratizado do ensino (GOHN, 2014), foi adotado o currículo da Secretaria de Educação de Pernambuco destinado ao ensino fundamental, no tocante ao eixo arte/música na escola, referenciado pelo objeto de conhecimento do currículo patrimônio cultural. Através dele, foi possível construir um repertório com interação prévia entre educador social e as crianças usando o aplicativo de Whatsapp de seus responsáveis, ratificando que a prática pedagógica deve estar respaldada num ambiente democrático, no qual professor e aluno dialoguem sobre os processos utilizados na construção da aprendizagem conforme afirma Freire (1996). Por conseguinte, a seleção das músicas deveria comunicar um enredo que valorizasse as diferentes culturas, ao mesmo tempo que contemplasse o alento, a empatia e a esperança de um ano de 2021 promissor com a vacinação contra a covid 19. Destarte, a diretriz curricular comunica os seguintes preceitos:

(EF69AR34PE) Analisar e valorizar o patrimônio cultural, material e imaterial, de culturas diversas, em especial a local e a brasileira, incluindo suas matrizes indígenas, africanas e europeias, de diferentes épocas e estéticas, favorecendo a construção de vocabulário e repertório relativos às diferentes linguagens artísticas (PERNAMBUCO, 2018, p. 335). Grifo Nosso.

A partir do currículo quatro músicas foram escolhidas para constituição do repertório, respeitando o cotidiano religioso dos aprendizes, foram elas: Asa Branca (Luiz Gonzaga); Descansarei (Comunidade

\footnotetext{
${ }^{1}$ Expressão inglesa usada para confinamento ou fechamento total. (GRUPO A TARDE, 2020). Disponível em: https://coronavirus.atarde.com.br/entenda-o-que-significa-lockdown/. Acesso em: 20 mar. 2021.
} 


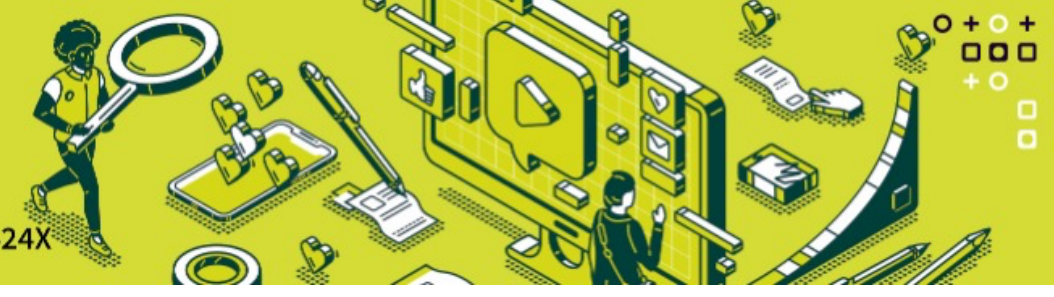

Evangélica de Maringá); A Casa é sua (Casa Worship) e Jingle Bells (Folclore Americano), corroborando o que afimaram, Cuervo e Pedrini (2010, p. 56):

[...] que o repertório possui papel estruturante no planejamento pedagógico-musical, e que precisamos construir uma relação equilibrada entre as preferências musicais dos alunos e a ampliação dessas preferências através da ludicidade e do estudo dinâmico, potencializado pelas possibilidades que a música contemporânea também oferece.

Ponderando sobre tal assertiva, o planejamento das aulas com seus respectivos objetivos e conteúdos a serem trabalhados, assim como a metodologia adotada a cada encontro, formou-se o quadro a seguir:

Quadro 1: Plano de aulas para o estudo remoto da flauta doce

\begin{tabular}{|c|c|c|c|c|}
\hline Datas & $\begin{array}{l}\mathbf{N}^{\circ} \text { de } \\
\text { Aulas }\end{array}$ & Objetivos & Conteúdos & Metodologia \\
\hline $02 / 10$ & 01 & $\begin{array}{l}\text { Conhecer a história } \\
\text { artística de Luiz } \\
\text { Gonzaga e o contexto } \\
\text { da música Asa Branca. }\end{array}$ & $\begin{array}{l}\text { Luiz Gonzaga e a } \\
\text { Música Asa Branca. }\end{array}$ & $\begin{array}{l}\text { Os alunos assistirão a entrevista de Luiz Gonzaga a apresentadora } \\
\text { Leda Nagle em } 1987 \text { e logo após se ampliará em discussão os } \\
\text { pontos tratados na entrevista.Disponívelem: } \\
\text { https://www.youtube.com/watch?v=DWuW3CAhMfk }\end{array}$ \\
\hline $\begin{array}{l}09 \text { e } \\
16 / 10\end{array}$ & 02 & $\begin{array}{l}\text { Executar a melodia Asa } \\
\text { Branca. }\end{array}$ & Melodia Asa Branca & $\begin{array}{l}\text { A escrita melódica será apresentada via Google Meet e cada aluno } \\
\text { tocará individualmente usando as notas sol3, lá3, si3, dó3 e ré } 4 \text {. }\end{array}$ \\
\hline $23 / 10$ & 01 & $\begin{array}{l}\text { Conhecer e identificar } \\
\text { características do } \\
\text { gênero MPB como } \\
\text { elemento estruturante } \\
\text { das músicas cristãs a } \\
\text { partir de meados da } \\
\text { década de } 1960 .\end{array}$ & $\begin{array}{l}\text { Música Popular } \\
\text { Brasileira } \\
\text { Melodia Descansarei }\end{array}$ & $\begin{array}{l}\text { Os alunos assistirão ao breve histórico da MPB. Disponível em: } \\
\text { https://www.youtube.com/watch?v=qvklwdDMHas } \\
\text { Em seguida se ampliará a discussão através da identificação de } \\
\text { alguns gêneros musicais encontrados na música cristã. }\end{array}$ \\
\hline $\begin{array}{l}30 / 10 \text { e } \\
06 / 11\end{array}$ & 02 & $\begin{array}{l}\text { Conhecer e executar } \\
\text { notas agudas na flauta } \\
\text { doce. }\end{array}$ & Melodia Descansarei & $\begin{array}{l}\text { A escrita melódica será apresentada via Google Meet e cada aluno } \\
\text { tocará individualmente usando ás notas agudas: mi4, fá\#4, e sol4 } \\
\text { além das outras notas já conhecidas. }\end{array}$ \\
\hline $13 / 11$ & 01 & $\begin{array}{l}\text { Conhecer o gênero } \\
\text { musical negro spiritual } \\
\text { e discutir sobre } \\
\text { escravidão e racismo. }\end{array}$ & $\begin{array}{l}\text { Gênero Negro } \\
\text { Spiritual; Racismo }\end{array}$ & 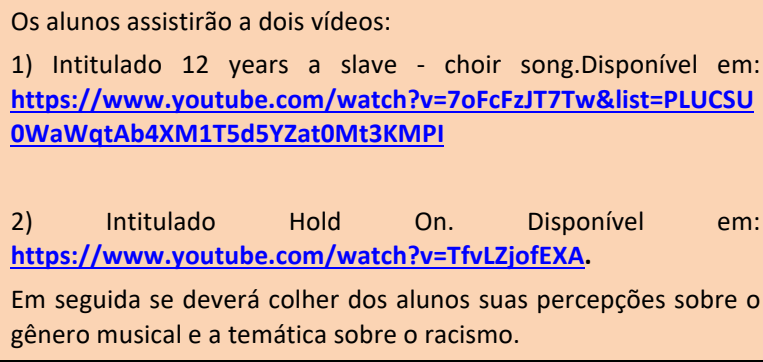 \\
\hline $\begin{array}{l}20 \text { e } \\
27 / 11\end{array}$ & 02 & $\begin{array}{l}\text { Conhecer e executar } \\
\text { notas musicais ainda } \\
\text { não vistas. }\end{array}$ & Melodia A Casa é Sua. & $\begin{array}{l}\text { A escrita melódica será apresentada via Google Meet e cada aluno } \\
\text { tocará individualmente usando as notas Mi3 e Fáł\#3. }\end{array}$ \\
\hline $04 / 12$ & 01 & $\begin{array}{l}\text { Executar a canção } \\
\text { folclórica Jingle Bells. }\end{array}$ & Melodia Jingle Bells. & $\begin{array}{l}\text { A escrita melódica será apresentada via Google Meet e cada aluno } \\
\text { tocará individualmente usando as notas que já são conhecidas. }\end{array}$ \\
\hline $11 / 12$ & 01 & $\begin{array}{l}\text { Realizar prática de } \\
\text { conjunto com alunos } \\
\text { que executam } \\
\text { instrumentos } \\
\text { harmônicos } \\
\text { Percussivos. }\end{array}$ & $\begin{array}{l}\text { Ensaio Prática de } \\
\text { Conjunto. }\end{array}$ & $\begin{array}{l}\text { As flautas executarão as melodias estudadas e internalizarão as } \\
\text { harmonias e arranjos construídos para acompanhamento do grupo } \\
\text { instrumental. }\end{array}$ \\
\hline $18 / 12$ & 01 & $\begin{array}{l}\text { Registrar a construção } \\
\text { da prática musical } \\
\text { através do áudio } \\
\text { visual. }\end{array}$ & Prática de Conjunto. & $\begin{array}{l}\text { A execução acontecerá como se estivessem apresentando para } \\
\text { uma plateia, enquanto isso, a equipe de mídia registra a } \\
\text { espontaneidade dos pequenos músicos e musicistas. }\end{array}$ \\
\hline
\end{tabular}

Elaboração: Os Autores, 2021. 


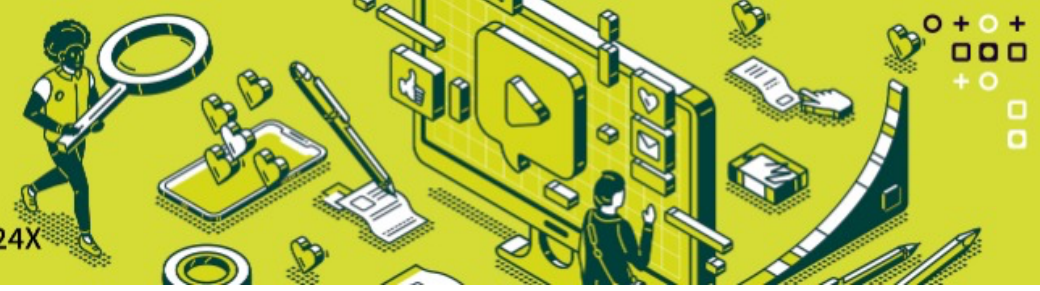

Sabe-se que a flauta doce como outros instrumentos musicais tem sua família, as quais são caracterizadas por tonalidades, timbres e extensões diferentes. Naquele cenário, de iniciação ao estudo do instrumento, foi utilizada a flauta doce soprano com dedilhado Barroco, por apresentar uma melhor qualidade sonora quando comparada a produção do modelo popular conhecido como germânico, o qual pode ser encontrado tanto nas lojas de instrumentos musicais oficiais quanto nas feiras livres. Segundo Cuervo (2009, p. 26):

Aconselha-se a utilização da flauta doce modelo barroco por utilizar parâmetros baseados em registros históricos de fabricação artesanal, afinação e digitação, corroborando, também, a uniformização de elementos técnicos como dedilhado. o modelo germânico foi uma tentativa, no século XX, de facilitação de alguns dedilhados, o que, porém comprometeu a qualidade timbrística e afinação de algumas notas.

Um ponto que mereceu destaque nessa experiência, foi a prática do instrumento no cotidiano dos alunos, a qual ficava evidente a cada aula, isto porque, a cada encontro os mesmos conseguiam demonstrar a evolução dos seus estudos no uso da memória, dedilhado e afinação. Ao final dos dez encontros, foi marcado um ensaio geral presencial para a atividade da prática de conjunto, cujos outros instrumentos formados pela percussão, teclados e violão foram executados por outros participantes a convite do educador social, visto que também participaram de outras oficinas musicais disponibilizadas pela organização não governamental durante outros dias e horários.

\section{RESULTADOS E DISCUSSÃo}

No ensaio geral foi possível socializar os arranjos para todo o grupo, tendo as flautas realizando as melodias das músicas do repertório e em alguns momentos conseguindo alguns duetos. Após o ensaio com acompanhamento harmônico e percussivo, foi marcada a gravação audiovisual com a finalidade de ser transmitida pelas redes sociais: Facebook e Instagran, no dia 24 de dezembro de 2020. Uma vez gravado, o vídeo contou com abertura e o encerramento organizado por uma das flautistas, que fazendo uso de um poema de cordel idealizado pelo educador social, trouxe um enredo que instigava a importância da fé e na esperança em que dias melhores estavam por vir.

A adoção do cordel deveu-se à referência à literatura nordestina, ao mesmo tempo que a música Asa Branca fez parte do repertório executado, lembrando a vida sofrida do nordestino com a seca e a fome recorrentes, que apesar de uma trajetória tão árida, de uma "Vida Severina", como povo forte que é, encontra-se firme na luta por dias melhores. Em continuidade foi o momento do repertório religioso e na conclusão, a declamação do texto desejando à audiência um 2021 repleto de saúde, paz e amor ao som do popular Jingle Bells. O audiovisual teve a duração de nove minutos e treze segundos e pode ser assistido através do acesso à plataforma do Facebook com acesso público, sob o seguinte endereço eletrônico: https://www.facebook.com/misericordiaonline/videos/167207771854311.

\subsection{Os SONS IDEOLÓGICOS NOS DISCURSOS dOS ENTREVISTADOS}

Como fundamentação teórica e metodológica aplicou-se os preceitos da Análise de Discurso (AD), a fim de compreender os significados trazidos pelo estudo da flauta doce tanto para os responsáveis quanto para os alunos. Os dois quadros a seguir oferecem uma visão geral do processo de entrevistas, conjugando as perguntas apresentadas e a que objetivos se vinculavam. 


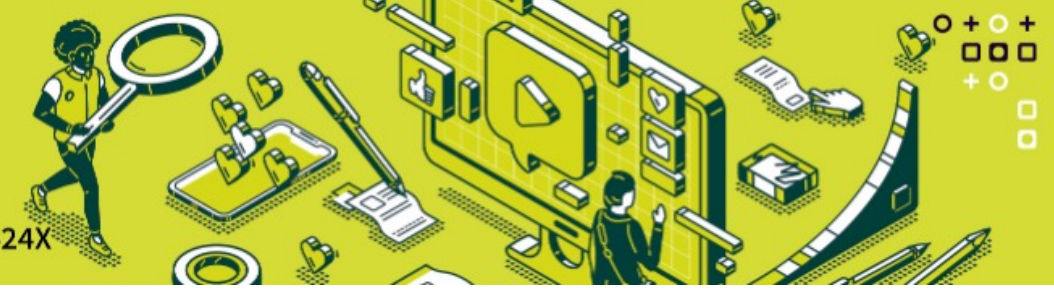

Quadro 2: Sobre os responsáveis pelos alunos

\begin{tabular}{|l|l|}
\hline Tópicos & Objetivos \\
\hline $\begin{array}{l}\text { O que você acha do instrumento flauta } \\
\text { doce? }\end{array}$ & $\begin{array}{l}\text { Identificar ideologias discursivas presentes nos } \\
\text { discursos dos responsáveis sobre o instrumento } \\
\text { musical. }\end{array}$ \\
\hline $\begin{array}{l}\text { Você incentiva sua criança a estudar o } \\
\text { instrumento? }\end{array}$ & $\begin{array}{l}\text { Conhecer dos responsáveis se existe incentivo a prática } \\
\text { instrumental. }\end{array}$ \\
\hline $\begin{array}{l}\text { Fale sobre suas emoções, a partir do } \\
\text { momento que presencia sua criança } \\
\text { executando peças musicais em uma } \\
\text { apresentação. }\end{array}$ & $\begin{array}{l}\text { Identificar nos discursos emoções oriundas da prática } \\
\text { instrumental das crianças. }\end{array}$ \\
\hline $\begin{array}{l}\text { Você acha importante sua criança estudar } \\
\text { música? Explique. }\end{array}$ & $\begin{array}{l}\text { Identificar nos discursos dos responsáveis seus níveis de } \\
\text { compreensão a respeito aos benefícios propiciados } \\
\text { pelo estudo da música. }\end{array}$ \\
\hline
\end{tabular}

Elaboração: Os Autores, 2021.

Quadro 3: Sobre os Alunos

\begin{tabular}{|l|l|}
\hline Tópicos & Objetivos \\
\hline Você gosta de tocar flauta doce? Por quê? & $\begin{array}{l}\text { Conhecer os motivos que fazem o aluno estudar o } \\
\text { instrumento. }\end{array}$ \\
\hline $\begin{array}{l}\text { Você acha que a prática da música auxilia em } \\
\text { outras áreas da vida, como: concentração, } \\
\text { respeito e disciplina? }\end{array}$ & $\begin{array}{l}\text { Identificar através da percepção dos alunos as } \\
\text { sóciocognitivos. }\end{array}$ \\
\hline
\end{tabular}

Elaboração: Os Autores, 2021.

As perguntas foram endereçadas aos responsáveis via aplicativo Whatsapp em razão da normativa sobre o distanciamento social, negociando com os mesmos o prazo máximo de uma semana para reenviarem as respostas. Sublinha-se que os entrevistados foram orientados a gravarem seus áudios, uma vez que no processo de análise a entonação da voz no discurso pode comunicar significados (ORLANDI, 2005).

\subsection{SOBRE A ANÁLISE DE DISCURSO}

Partindo do pressuposto que a interação humana proporcionada pela linguagem é de alta relevância, em particular nos processos educativos e que nesse processo desenvolvem-se a cultura e o conhecimento, considerando que a música lhe é semelhante, seja pelos aspectos sonoros, por meio da fonologia ou pelos simbólicos, como nos estudos semânticos, afinal a execução musical compartilha sentidos de acordo com os seus apreciadores e mesmo entre os musicistas. Se por um lado alguns teóricos consideram apenas como linguagem os pontos de interseção com a sonoridade, outros atribuem as relações de sentido e por conseguinte de significação a cada experiência do indivíduo com a música. Sobre isso

Pela escuta moderna, o que é escutado é a significante e não o significado da obra que é a estrutura intencional criada por um autor. O que se escuta aí é a construção desse significado de acordo com seu receptor. Por exemplo, ao escutar uma obra clássica, o auditor opera uma descodificação da obra em função da sensibilidade e da formação dele (RIOM, 2017, p. 279). 


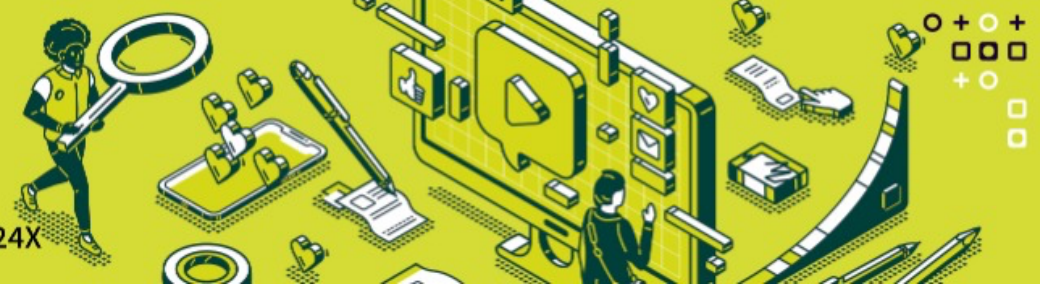

Assim, como apresenta Dra. Riom, ao estudar alguns textos do filósofo e semiólogo Roland Barthes, quando ele se aproximou de escritores que também eram músicos, a fim de fazer, segundo ela, uma "leitura do sensível", sendo possível observar a relação entre a execução da música e o significado gerado, variando de acordo com a sensibilidade e a formação do ouvinte. A propósito daquela análise para além das sequências sonoras, suas harmonizações ou mesmo as letras das canções, foi possível refletir sobre os caminhos da Escuta e sua repercussão, legando-nos observações preciosas envolvendo diversas áreas do conhecimento como a psicanálise, na busca pela audição do inconsciente: "Escutar a voz do outro, é colocar-se em relação com ele" (IBIDEM, p. 277).

Ainda sobre a linguagem, é possível afirmar que ela é mediadora entre o indivíduo e a realidade, com suas ideias, seu tempo e as pessoas que o cercam, explicitando que é no lugar de conflito, no confronto ideológico, que ela pode ser estudada (BRANDÃO, 2004). Além desse aspecto há outros, como a posição sócio histórica dos enunciadores e as condições de produção do que enunciam. Imprescindíveis na Análise do Discurso esses elementos serão fundamentais para a observação das categorias presentes nas falas dos colaboradores, pais e estudantes, compartilhadas por meio das entrevistas.

No que diz respeito às condições de produção, para Eni Orlandi "compreendem fundamentalmente os sujeitos e a situação." (2005), no caso em estudo, identificamos o ambiente virtual em que ocorreram as aulas, as situações de ajustes necessários aos participantes como o acesso à internet, o smartphone ou computadores, um espaço para assistir as aulas e ensaiar, o apoio da família nas atividades, cada elemento foi essencial para a produção dos discursos enunciados por cada pessoa entrevistada.

Ainda como afirma a pesquisadora, na mesma obra, acerca do contexto da produção do discurso e dos efeitos de sentidos desses dizeres, a partir da posição que os participantes ocupam em relação às aulas: "As palavras mudam de sentido segundo as posições daqueles que as empregam. Elas "tiram" seu sentido dessas posições, isto é, em relação às formações ideológicas nas quais essas posições se inscrevem." (ORLANDI, 2005). Desse modo, pode ser lido nas transcrições a seguir, que pais e estudantes relacionaram-se de forma distinta com a experiência de aulas de flauta doce à distância, cada qual experimenta e se expressa de acordo com os saberes sociais adquiridos ao longo da própria vida e das escutas de seus pares dentro e fora do círculo familiar.

Considerando as afirmações anteriores foram averiguadas três categorias destacadas nos discursos compartilhados durante as entrevistas, são percepções, emoções, ideologias presentes na leitura de mundo, no caso, da vivência de aulas em formato remoto, em um cenário de pandemia, intercalando com períodos de distanciamento social mais e menos intenso de acordo com as orientações das instituições de saúde pública do estado.

\subsubsection{O ESTUDO MUSICAL E A PROMOÇÃO DA DISCIPLINA E DA CONCENTRAÇÃO}

A busca pelo desenvolvimento de atividades que promovam a atenção e a concentração é constante no meio docente e porque não afirmar que entre os pais, visto que há muitos atrativos no ambiente virtual que podem favorecer ou reforçar a dispersão. Esse cenário muda de acordo com os participantes, sua idade e seu nível de engajamento durante as aulas. Considerando que os adultos em geral entendem que concentrar-se é sinônimo de concentração das energias para um tema ou objetivo em particular, não tiveram a mesma percepção os estudantes, como pode ser lido a seguir:

Estudante no 1: “(...) Quando eu comecei a tocar flauta doce, percebi que eu consigo fazer várias coisas ao mesmo tempo, como: me concentrar na letra e tocar ao mesmo tempo e me concentrar também na melodia." 


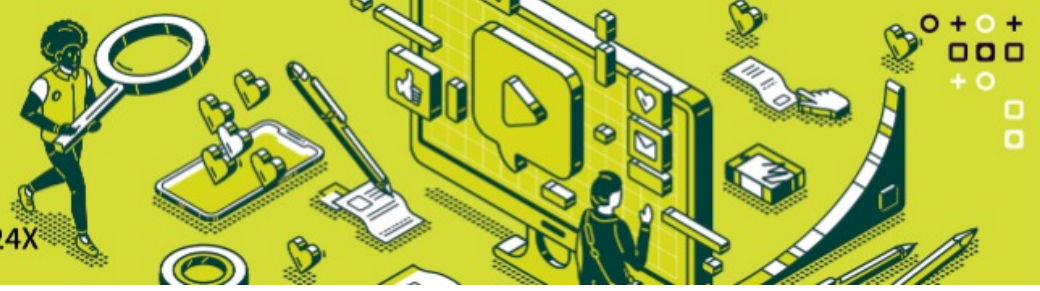

Estudante no 2: "Estudar música me ajudou na coordenação motora, a saber tocar as notas dela, a entender os ritmos e me ajudou na concentração também pra eu saber tocá-la."

Nos enunciados proferidos durante as entrevistas foi possível perceber os gestos de interpretação, como os sentidos variam de pessoa a pessoa, daí a afirmação de Orlandi: "O falante não opera com a literalidade como algo fixo e irredutível, uma vez que não há um sentido instituído historicamente na relação do sujeito com a língua e que faz parte das condições de produção do discurso." (2005). Desse modo para cada entrevistado a ideia sobre "concentração" foi diferente, enquanto para a primeira pessoa o destaque voltou-se para o sentido de executar atividades diferentes de forma simultânea, para a segunda, representava habilidade para os aspectos técnicos a boa execução da música. Houve assim deslocamentos de sentidos a partir das experiências individuais de cada sujeito com o instrumento musical, ou mesmo com a própria aprendizagem.

\subsubsection{A MÚSICA COMO APAZIGUADORA}

É comum aos educadores, ouvir dos pais e responsáveis queixas acerca da inquietação típica dos estudantes, transitando entre a infância e a adolescência, sobre a dificuldade em fazê-los aquietarem-se para ler ou executar as conhecidas tarefas para casa. De igual modo, há uma certa frequência, dessa feita não apenas por parte de pais, da ideia de que certos gêneros musicais promovem efeito de relaxamento, uma sensação apaziguadora e em razão disso contribuem para criar um ambiente agradável a toda a família. Tal aspecto terapêutico tem escopo teórico e livre aceitação na sociedade, daí os excertos abaixo serem portadores dessa ideia, que ecoa no tempo e no espaço social há certo tempo e foi assumido como verdade pelos entrevistados.

Responsável no 5: "Fico muito emocionada ao ver, quando ela fica dedicada a aprender a música, ela aprende, ela fica satisfeita.... e ela...e a música traz uma paz, traz uma alegria né? E eu fico muito feliz, um sentimento muito de orgulho né, em vê-la tocando"

Responsável $n^{\circ} 5$ : “Como o nome já diz, né, flauta doce, é muito agradável vê.....é.... ela tocando, né, é um instrumento muito gostoso de ouvir..."

É possível ainda notar que o responsável 5 relaciona o nome do instrumento musical ao que qualifica como "agradável", "gostoso", com a finalidade de traduzir as emoções a que associa a escuta musical, como alegria, orgulho, prazer, seja em razão da sonoridade, seja em resposta positiva da criança ao demonstrar habilidade com o instrumento, exemplo do interdiscurso, em que é possível identificar que as referências sobre o tema são anteriores ao falante, são vozes de antecessores, próximos ou não, que reiteradas vezes se referiram à música como relaxante, calmante.

Percebeu-se também a presença da polissemia, ou seja, a diversidade de sentidos que os vocábulos podem expressar de acordo com o contexto em que foi produzido ou compartilhado o discurso. No caso, os adjetivos escolhidos remetem ao que há de positivo como a palavra "doce", que aqui manifestou o sentido de agradável, o mesmo não ocorrendo se atribuída a um aroma, a uma fragrância que nem sempre é bem tolerada.

\subsubsection{A ARTE COMO TRANSFORMADORA/ RESTAURADORA DO CARÁTER HUMANO}




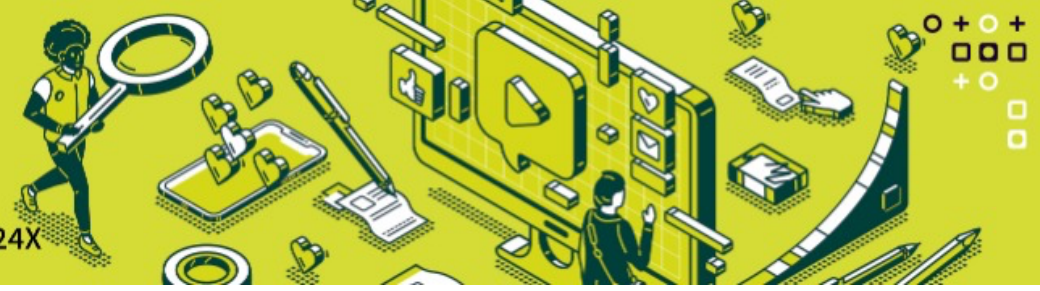

A música assim como as demais manifestações artísticas são vistas pela sociedade como portas abertas para o desenvolvimento de habilidades e aquisição de saberes que tornam a vida com seus desafios mais criativa, diversificada, uma vez que amplia a percepção sobre as relações humanas, sobre as formas de expressão das emoções e das ideias. É com essa percepção que os entrevistados, aqui identificados como responsáveis expuseram suas impressões acerca do papel da aula de música na educação das crianças:

Responsável no 2: “Querendo ou não na música uma pessoa aprende a ter paciência, a ter calma a esperar sua vez, a fazer junto com o outro (coletividade), a fazer perfeito, ser perseverante, repetir quantas vezes for necessário para alcançar a perfeição juntos com o outro."

Responsável no 4: "sabemos que a música ela tem essa força, esse poder de transformar, de ajudar na formação do caráter de um ser humano. Então, isso nos alegra, eu.... gosto muito."

Ao ler os trechos anteriores em que duas pessoas adultas responderam sobre a relevância do estudo da música, embora de famílias, idades, profissões diferentes, as respostas apresentam uma similaridade na ideia de que a arte pode contribuir positivamente para suas crianças, explicitando que nesse discurso não há ineditismo, que esses não são os sujeitos originários do que ora afirma, mas como a Análise de Discurso registrou, "A forma-sujeito histórica que corresponde à da sociedade atual representa bem a contradição: é um sujeito ao mesmo tempo livre e submisso." (ORLANDI, 2005, p. 50). Assim, é natural que haja semelhança entre as falas uma vez que ambos os entrevistados estão inseridos em um mesmo espaço e tempo social em que transitam impressões e ideias equivalentes, é o intradiscurso revelado, a formulação da atualidade, das condições disponíveis interferindo na memória e por conseguinte no dizer.

\section{CONSIDERAÇõES FINAIS}

A flauta doce como instrumento milenar se apresenta como um importante meio de iniciação aos estudos musicais. A história da música registra que reis e nobres, dela se utilizaram a fim de experimentarem a sensação de executar um instrumento e produzirem música. Na contemporaneidade, o fato de ser um instrumento leve, pequeno e parecido com a voz humana acentua sua aquisição para o processo de musicalização.

Evidentemente que para alguns, a flauta doce não é bem vinda em seus ambientes domésticos, talvez isto aconteça devido a uma metodologia não adequada por parte do docente, resultando em dificuldades no desenvolvimento do aluno e desta feita causando insatisfação nos pais e/ou responsáveis, ou devido à sua tessitura, que por ser um instrumento agudo pode trazer alguma irritação ao ouvinte. Contudo, repara-se que quando bem empregada, independente do modelo de ensino, seja presencial ou remoto, há grandes possibilidades de se obter resultados satisfatórios.

Por conseguinte, é sabido que o estudo de um instrumento musical possibilita variados benefícios a quem o estuda, conforme se pode ratificar nesse estudo, a saber: concentração, coordenação motora, memorização e trabalho em grupo (coletividade). Assim, em tempos de pandemia de covid 19, a prática da flauta doce se apresenta como um importante meio terapêutico, a fim de permitir alegria aos lares seja para quem a executa ou para quem a escuta.

É relevante destacar que o formato de ensino remoto evidenciou aspectos importantes para as famílias, como a fragilidade dos relacionamentos, ampliadas em razão da longa permanência dos parentes em um mesmo espaço, que por vezes em razão da diminuta extensão física gerou desconfortos e atritos. Para 


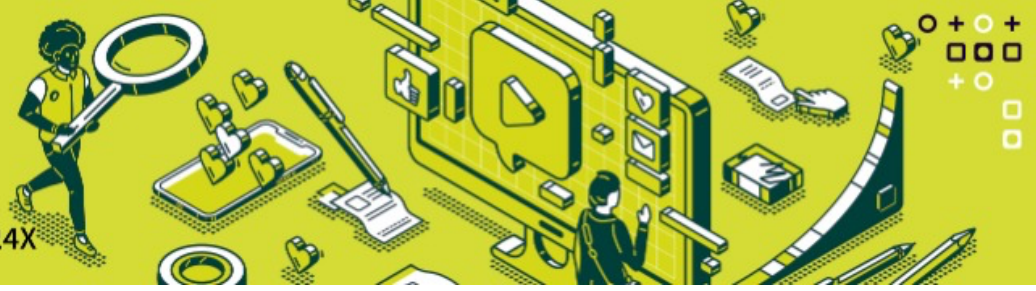

além dos fatores emocionais, acrescente-se os de ordem econômica e de saúde, que contribuíram para criar ambientes de tensão constante, sendo ainda mais relevante a busca por alternativas terapêuticas a fim de promover o equilíbrio e a harmonia familiar.

\section{REFERÊNCIAS}

AGUILAR, Patrícia Michelini. A flauta doce no Brasil: da chegada dos jesuítas á década de 1970. 2017. Tese (Doutorado em Música) - Universidade de São Paulo, São Paulo, 2017.

ALEPE, Legis. Decreto $\mathrm{n}^{\circ}$ 48.809, de 14 de Março de 2020 . Disponível em: https://legis.alepe.pe.gov.br/texto.aspx?tiponorma $=6 \&$ numero $=48809 \&$ complemento $=0 \& a n o=2020 \&$ ti po=\&url. Acesso em: 13 jan. 2021.

BAND. Especialistas analisam expectativas para o Brasil em 2020. Disponível em: https://www.metroworldnews.com.br/foco/2020/01/06/expectativas-brasil-2020.html. Acesso em: 6 mar. 2021.

BARBOSA, Fabiano Da Silva. A flauta doce:um instrumento musicalizador dos tempos modernos. Revista Científica Multidisciplinar Núcleo do Conhecimento. v. 3, p. 126-150, Maio 2020. Disponível em: https://www.nucleodoconhecimento.com.br/arte/flauta-doce. Acesso em: 19 jun. 2021.

BENASSI, Claudio Alves. A flauta doce: a história do percurso desse instrumento na música contemporânea. Revista Eletrônica discente História.com, Cachoeira, v. 1, n. 1, p. 1-16, 2013. Disponível em: https://www3.ufrb.edu.br/ojs/index.php/historiacom/article/view/3. Acesso em: 19 de jun. 2021.

BENNETT, Roy. Uma breve história da música. Tradução: Maria Teresa Resende Costa. Rio de Janeiro: Jorge Zahar, 1986.

BRANDÃO, Helena Hathsue Nagamine. Introdução à análise do discurso. - 2ª ed. Ver. - Campinas, SP: Editora da UNICAMP, 2004.

BRASIL. Portaria 343, de 17 de março de 2020. Dispõe sobre a substituição das aulas presenciais por aulas em meios digitais enquanto durar a situação de pandemia do Novo CoronaVírus - COVID - 19. Disponível em: http://www.planalto.gov.br/CCIVIL_03/Portaria/PRT/Portaria\%20n\%C2\%BA\%20343-20-mec.htm. Acesso em: 19 jun. 2021.

CAMPOS, Flávio Tau de Souza. Recompletamento de efetivo e veículos. In: Polícia Civil de Pernambuco Delegacia de Polícia da $15^{\circ}$ Circunscrição Policial Alto do Pascoal. Recife, 2015. Disponível em: http://adeppe.com.br/wp-content/uploads/2015/04/CI-016-2015-Alto-do-Pascoal.pdf. Acesso em: 14 mar. 2021.

CORRÉA, Douglas. Fio Cruz Orienta sobre higienização correta para evitar covid-19: uma das formas de contagio é o contato com superfícies contaminadas. In: AGÊNCIA BRASIL. Rio de Janeiro, 2020. Disponível em: https://agenciabrasil.ebc.com.br/saude/noticia/2020-05/fiocruz-orienta-sobre-higienizacaocorreta-para-evitar-covid-19. Acesso em: 23 jun. 2021.

CUERVO, Luciane da Costa. Musicalidade na Performance com a flauta doce. 2009. Dissertação (Mestrado em Educação) - Universidade Federal do rio Grande do Sul, Porto Alegre, 2009.

CUERVO, Luciane; PEDRINI, Juliana. Flauteando e Criando: experiências e reflexões sobre criatividade na aula de música. Música na Educação Básica. Associação Brasileira de Educação Musical. Porto Alegre, v. 2, n. 2, set. 2010. 


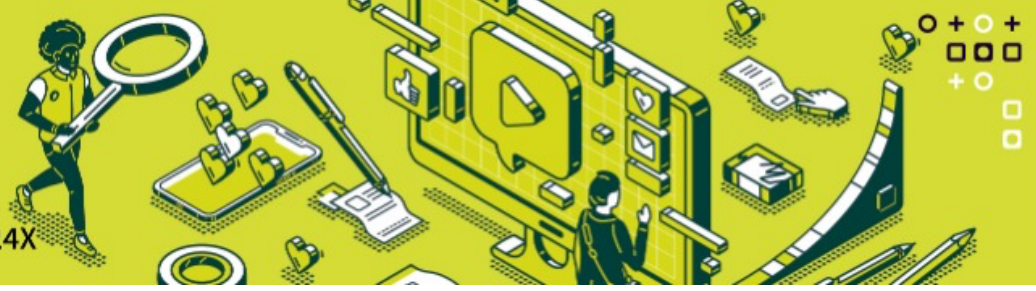

DIRENE, Regina Célia Pfutzenreuter. Caderno de história e prática musical da flauta Doce. In:Os desafios da escola pública paranaense na Perspectiva do professor PDE - Produções Didático-Pedagógicas. Paraná: Curitiba, 2014.2 Disponível em: http://www.diaadiaeducacao.pr.gov.br/portals/cadernospde/pdebusca/producoes_pde/2014/2014_un espar-curitibai_arte_pdp_regina_celia_pfutzenreuter_direne.pdf. Acesso em: 14 mar. 2021.

FOLHA DE PERNAMBUCO. Coronavírus: Igrejas e Templos religiosos aumentam capacidade de público a partir de segunda-feira (10). Disponível em: https://www.folhape.com.br/noticias/igrejas-e-templosreliogiosos-aumentam-capacidade-a-partir-da/149975/. Acesso em: 17 de fev. 2021.

FREIRE, Paulo. Pedagogia da autonomia: saberes necessários à prática educativa. 43. ed. São Paulo: Paz e Terra, 1996.

GOHN, Maria da Glória. Educação não formal, aprendizagens e saberes em processos participativos. In: Investigar em Educação: n. 1, p. 35-50, 2014.

MATEIRO, Teresa; ILARI, Beatriz Senoi. Pedagogias em educação musical. Curitiba: Ibpex, 2011.

MINISTÉRIO INTERNACIONAL DE MISERICÓRDIA. Estatuto. Recife, 2013.

ORLANDI, Eni. Análise do discurso: princípios e procedimentos. 4ạ Edição. Campinas - SP. Pontes, 2005.

PERNAMBUCO. Currículo de Pernambuco: Ensino Fundamental, Recife, 2018.

PRODANOV, Cleber Cristiano; FREITAS, Ernani Cesar de. Metodologia do Trabalho Científico. Métodos e Técnicas da Pesquisa e do Trabalho Acadêmico. 2 ed, Novo Hamburgo: Feevale, 2013.

RIOM, Charlotte Caroline. In: Anais do SEFIM - Revista interdisciplinar de Música, Filosofia e Educação. Revista on line. UFRGS. ISSN: 2525-3778 v. 3, n. 3 (2017) Roland Barthes: A música como linguagem do corpo (p. 271- 282).

SOPRANA, Paula. 70 milhões de brasileiros tem acesso precário à internet na pandemia do corona vírus. Disponível em: https://www1.folha.uol.com.br/mercado/2020/05/cerca-de-70-milhoes-no-brasil-temacesso-precario-a-internet-na-pandemia.shtml. Acesso em: 19 jun. 2021.

VARGAS, Maryléa Elizabeth Ramos. Influências da Música no comportamento humano: explicações da Neurociência e Psicologia. In: CONGRESSO INTERNACIONAL DA FACULDADE EST, 2012, São Leopoldo. Anais. São Leopoldo:EST, 2012. p. 944-956. 